\title{
Measurements of the Stiffness and Thickness of the Pavement Asphalt Layer Using the Enhanced Resonance Search Method
}

\author{
Nur Mustakiza Zakaria, ${ }^{1}$ Nur Izzi Md. Yusoff, ${ }^{1}$ Sentot Hardwiyono, ${ }^{2}$ \\ Khairul Anuar Mohd Nayan, ${ }^{1}$ and Ahmed El-Shafie ${ }^{1}$ \\ ${ }^{1}$ Department of Civil \& Structural Engineering, Universiti Kebangsaan Malaysia, 43600 Selangor, Malaysia \\ ${ }^{2}$ Department of Civil Engineering, Universitas Muhammadiyah, Yogyakarta 55183, Indonesia \\ Correspondence should be addressed to Nur Izzi Md. Yusoff; izzi@ukm.edu.my
}

Received 22 May 2014; Accepted 21 July 2014; Published 3 September 2014

Academic Editor: Ching-Tai Ng

Copyright (C) 2014 Nur Mustakiza Zakaria et al. This is an open access article distributed under the Creative Commons Attribution License, which permits unrestricted use, distribution, and reproduction in any medium, provided the original work is properly cited.

\begin{abstract}
Enhanced resonance search (ERS) is a nondestructive testing method that has been created to evaluate the quality of a pavement by means of a special instrument called the pavement integrity scanner (PiScanner). This technique can be used to assess the thickness of the road pavement structure and the profile of shear wave velocity by using the principle of surface wave and body wave propagation. In this study, the ERS technique was used to determine the actual thickness of the asphaltic pavement surface layer, while the shear wave velocities obtained were used to determine its dynamic elastic modulus. A total of fifteen locations were identified and the results were then compared with the specifications of the Malaysian PWD, MDD UKM, and IKRAM. It was found that the value of the elastic modulus of materials is between $3929 \mathrm{MPa}$ and $17726 \mathrm{MPa}$. A comparison of the average thickness of the samples with the design thickness of MDD UKM showed a difference of 20 to $60 \%$. Thickness of the asphalt surface layer followed the specifications of Malaysian PWD and MDD UKM, while some of the values of stiffness obtained are higher than the standard.
\end{abstract}

\section{Introduction}

Flexible pavement is a composite material that consists of a mixture of aggregate, sand, bitumen, and filler material which provides a road surface with sufficient skid resistance and function to disseminate vehicle load to the subgrade and at the same time has a long life expectancy without the need for frequent maintenance. Pavement is designed with regard to major aspects, namely, the thickness, strength, resistance to surface water, and texture of the surface, to ensure that it can work properly. The objectives of pavement design generally involve the selection of building materials and ensuring that the thickness of each layer is correct to ensure that the flexible pavement layer is able to protect the subgrade from the impact of the traffic load [1].

However, the quality of flexible pavement decreases over time and depends on the quality of the materials used, the environmental conditions, and the traffic load exerted. Increased traffic load on old road infrastructure will result in a decrease in the thickness of the flexible pavement, shortening its lifespan [2]. Therefore, the exact thickness of each layer should also be emphasized in order to avoid damage occurring to the pavement as a result of the traffic load and the environment. The main aspects that need to be considered in road pavement management systems are an assessment of the current stiffness and the predicted pavement strength in the future [3]. The strength of flexible pavement can be determined by the elastic modulus parameter; this parameter is significant in predicting and evaluating the performance of flexible pavement when static and repetitive traffic loads are applied [4].

In general, falling weight deflectometer (FWD) is widely used equipment or tool to identify stiffness of the pavement system. The FWD is an experimental method of nondestructive test (NDT) which imposes an impulse load on the pavement surface through a circular steel plate where the stiffness of pavement layers system was evaluated by measuring maximum dynamic displacements. The FWD 
data contains environmental data, layer thickness, material response functions, and traffic load information. This testing tool is widely used as it is easily performed with good and efficient results. Meanwhile, ground penetrating radar (GPR) is another tool that can be used for measuring pavement thickness. To capture the pavement layer systems, a survey vehicle was used to place an antenna that received short pulses of electromagnetic energy from the pavement. The series of pulse will form a radar waveform that contains a record of the properties and thickness of the pavement layers system. This tool is accurate and nondestructive technique for evaluation of pavement layers system.

Recently, Joh et al. [5] developed a new tool, known as a pavement integrity scanner (PiScanner), to evaluate the stiffness for pavement layers system and, at the same time, the thickness of the pavement can be identified. In this study, the enhanced resonance search (ERS) method was used to determine the thickness and stiffness of the asphalt surface layer by using PiScanner. The PiScanner based on the ERS method has been tested earlier on rigid pavement structures; however, the applicability of this equipment for flexible pavement has yet to be investigated. Therefore, this study is conducted to identify the effectiveness of the PiScanner on flexible pavement in determining the thickness of the existing pavement system. The stiffness of the flexible pavement also will be determined, based on the theory of elasticity. However, the evaluation of flexible pavement structure will concentrate only on the asphalt surface layer, which is a combination of the wearing and binder courses.

\section{Enhanced Resonance Search (ERS) Method}

The thickness of the asphalt layer was determined using the ERS method. This method is a combination of the SASW and resonance method, whereby SASW determines the shear wave velocity profile and the thickness of the asphalt is determined using a resonance search $[5,6]$. Due to the inadequacy of measuring the pavement layer thickness by SASW, a resonance search of the pavement layer is used to ensure that the thickness of the pavement layer is determined accurately. SASW is used to evaluate the strength of the pavement system and concrete structure using surface wave velocity to determine the elastic properties of the material [7]. This method is also able to determine the elastic modulus and thickness of a layered system by fully utilising the advantages of surface waves [8].

An automation algorithm was developed by Joh et al. [5], for which this new algorithm was used to ease vertical profiling of concrete modulus in rigid pavement because conventional computation requires 15 to 30 minutes to compute theoretical modelling of wave propagation. By using this algorithm, approximately 3 to 5 minutes was taken for the analysis time. Two processes, namely, phase velocity calculation and resonance search, were using this automation algorithm. In automated phase velocity calculation, the fundamental wave group is extracted from the surface wave that propagates. Wave group in a Gabor spectrum will be examined for the extraction. While automated resonance search used iterative comparison of field measurements and theoretical model results in order to find accurate thickness, a resonant frequency from the frequency response curve was defined by using a theoretical modelling.

The use of the frequency domain over the time domain and the wave number of the $R$ wave transform analysis has several advantages, including the ease with which the solution to the wave propagation equation in the available frequency domain and the frequency and wave number analysis are obtained. This is because the analysis in the time domain using numerical integration is more complicated [9]. All information about wave propagation is obtained by the analysis of frequency and wave number [10]. Through frequency and wave number analysis, Nolet and Panza [11] show that the production of a spectrum is very convincing. In addition, the use of the Fourier transform has been developed to analyse the spectrum by numerical methods that can calculate digitally, known as the fast Fourier transform (FFT). This technique is able to measure and analyse dynamics systems in the frequency domain.

Body wave measurement is the measurement of the resonance method based on the variety reflection in bounded media. This method is stable in determining the dominant frequency of multiple wave reflections. One resonance method is the impact echo (IE) method. IE involves exerting an impact on the structure surface over a short period of time to produce low-frequency waves. The generated wave will propagate into the structure and then be reflected if there is a defect inside the structure or external borders [12].

\section{Determination of Stiffness}

According to the theory of wave propagation, the stiffness or the maximum shear modulus of the material under $0.0003 \%$ of strain can be determined from the velocity of $S$ wave propagation or shear wave [13]:

$$
G=\rho V_{S}^{2}
$$

Based on the elastic theory proposed by Yoder and Witczak [14], the elastic modulus of material can be described as

$$
E=2 G(1+\mu)=2 \rho V_{S}^{2}(1+\mu),
$$

where $G$ is shear modulus, $E$ is elastic modulus, $\rho$ is density, $V_{S}$ is $S$ wave velocity, and $\mu$ is Poisson's ratio.

\section{Methodology}

\subsection{Equipment}

4.1.1. PiScan Probe. The PiScan Probe (Figure 1(a)) consists of a sensor unit that uses an accelerometer for sensor wave propagation and this wave is created with an instrumented hammer (Figure 1(c)), which functions as an impulse generator. This apparatus is equipped with two accelerometers. The distance between the two accelerometers was adjusted to 0.15 and $0.30 \mathrm{~m}$ and there is a weight on each of the accelerometers. This weighting is to ensure that contact 


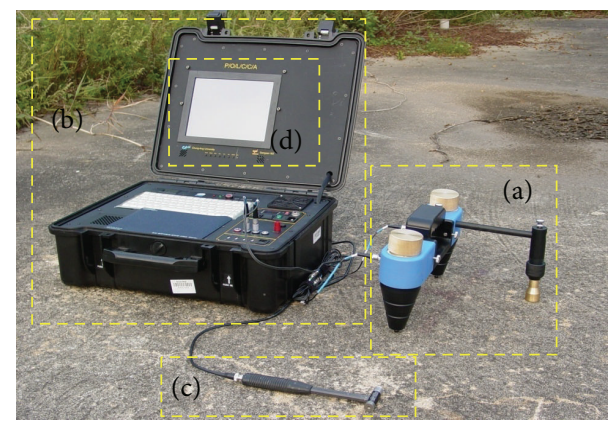

Figure 1: PiScanner system. (a) PiScan Probe, (b) POLCCA, (c) instrumented hammer, and (d) PiScanner Analyzer.

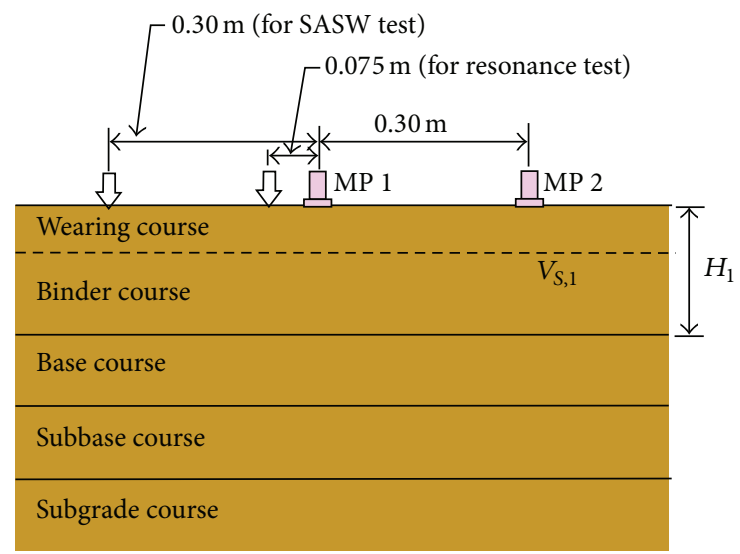

FIGURE 2: ERS measurement.

between the accelerometer and the pavement surface is perfect [5]. Therefore, any disturbance and the time interval of the detector can be eliminated. Joh et al. [5] explain that although the accelerometer in the PiScan Probe has a special frame, the measured signal is almost equal to the signal measured by the bare accelerometer.

4.1.2. POLCCA. POLCCA (Figure 1(b)) serves as a spectrum analyser that receives wave signals from the PiScan Probe. The wave signal in the form of amplitude and wave propagation time that is detected by the accelerometers will be recorded. POLCCA consists of a PiScan Analyser (Figure 1(d)) which functions as a data analyst equipped with dynamic signal analysis (DSA) or FFT analysis. The analyser performs the ERS measurement and analyses data measured automatically [5]. It is also equipped with a coupling AC/DC, four analogue channels, antidisguise filters, and an analogue trigger.

4.2. Set-Up of the ERS Method. The ERS method is a combination of the SASW and resonance methods. Thus, there are two ways to arrange the accelerometers and the impulse generator (Figure 2). For SASW or surface wave measurement, the measurement of the wave signal involves an instrumented hammer and two accelerometers. The distance between MP1 and MP2 is $0.30 \mathrm{~m}$ and the distance of the instrumented hammer from MP1 is equal to the distance between MP1 and MP2. The distance between the instrumented hammer and MP1 represents the assumed maximum depth. The resonance method involves an instrumented hammer and an accelerometer where the distance between the hammer and MP1 is $0.075 \mathrm{~m}$.

4.3. Site Location. The study focused on the structure of flexible pavement in the main campus of Universiti Kebangsaan Malaysia (UKM), Bangi, Selangor. The study area can be divided into two sections, namely, the first loop and the second loop, shown in Figure 3. A total of eight locations in the first loop and seven locations in the second loop were identified for measurement.

\section{Analysis and Discussion}

5.1. Procedure of ERS Analysis. In field data analysing, the ERS involves a combination of two methods. Therefore, this method consists of two main phases in the data analysis. The first phase is determining the shear wave velocity profile using SASW; the second phase involves determining the asphalt layer thickness. Surface wave analysis is done in advance to produce a graph of shear wave velocity versus depth so that a more accurate measurement of the asphalt layer thickness can be acquired from body wave analysis. Figure 4 shows details of the procedures involved.

5.2. Seismic Data Acquisition. There are four main steps involved in seismic data acquisition. The first is the placement of the accelerometer and impulse generator to produce waves. The second step is to set up the PiScanner Analyser to perform the measurement. The third and fourth steps are to measure the resonant body wave and the surface wave. The ERS measurement begins with two accelerometers placed on the pavement surface. These accelerometers should be touching the pavement surface without any holes to ensure that the data obtained are satisfactory. The hammer is then used to create a transient effect on the pavement at two positions, namely, $300 \mathrm{~mm}$ and $75 \mathrm{~mm}$ from the first accelerometer. The second step is to determine the settings for the PiScanner Analyser. The third step involves collecting body wave resonance signal data with the hammer set at $75 \mathrm{~mm}$ from the first accelerometer. Ten hammer blows are applied and the average of the resulting signal is recorded, as shown in Figure 5(a). The final step involved in seismic data acquisition is recording the surface wave. With a distance between the impact source and first receiver set at $300 \mathrm{~mm}$, ten hammer blows are applied and the average of the resulting signal is recorded, as shown in Figure 5(b).

5.3. Data Analysis. Data obtained from the field was analysed using automated algorithm analysis methods. The analysis was divided into two stages: the first stage is the velocity search phase and the second stage involves the resonant frequency search to determine the thickness of the asphalt surface layer. In the phase velocity search, the analysis begins with the production of the Gabor spectrum (Figure 6) of the impulse response. This consists of a group of resulting waves and the frequency of the wave group is used in filtering the pulse response (IR filtering, IRF) to produce a phase 


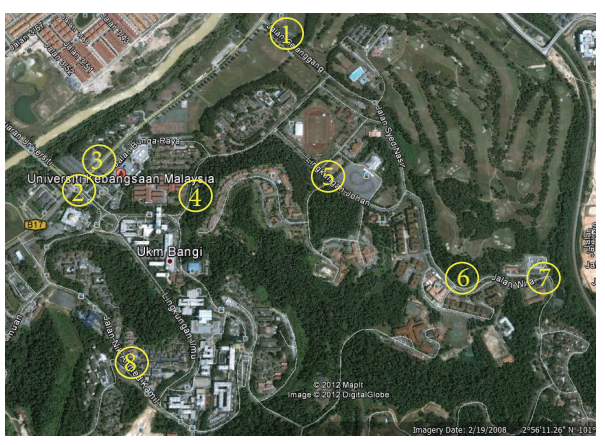

(a)

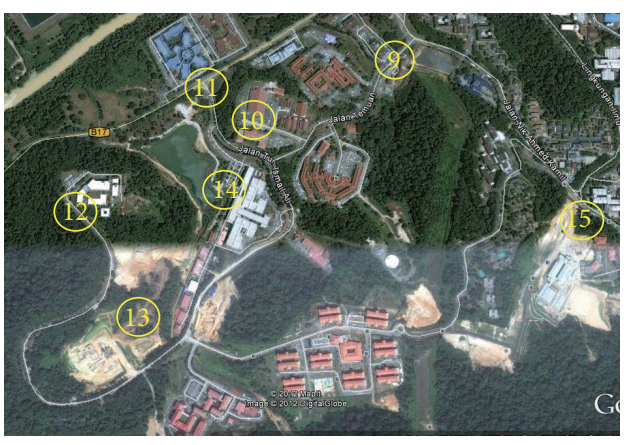

(b)

FIgURE 3: (a) Loop 1 and (b) Loop 2 of UKM campus.

Phase 1: determination of $V_{S}$ profile

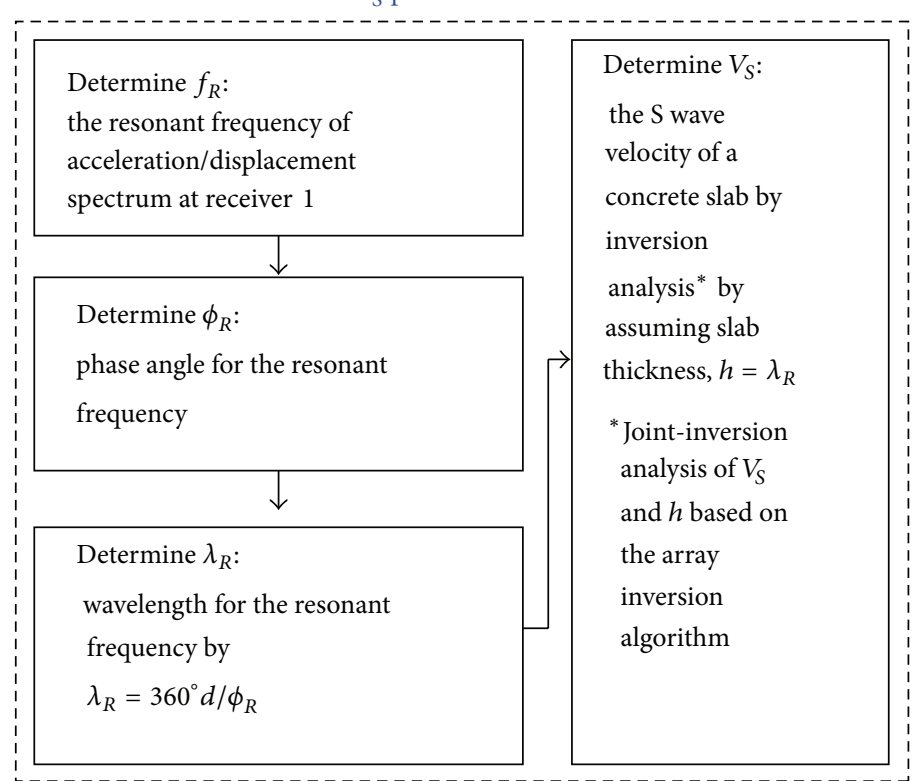

Phase 2: resonance search

for thickness determination

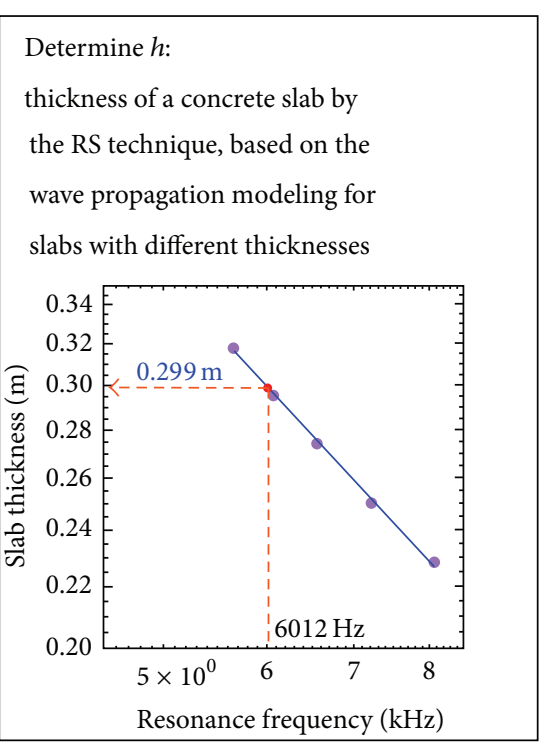

FIGURE 4: ERS method procedure (Cho et al., 2007 [6]).

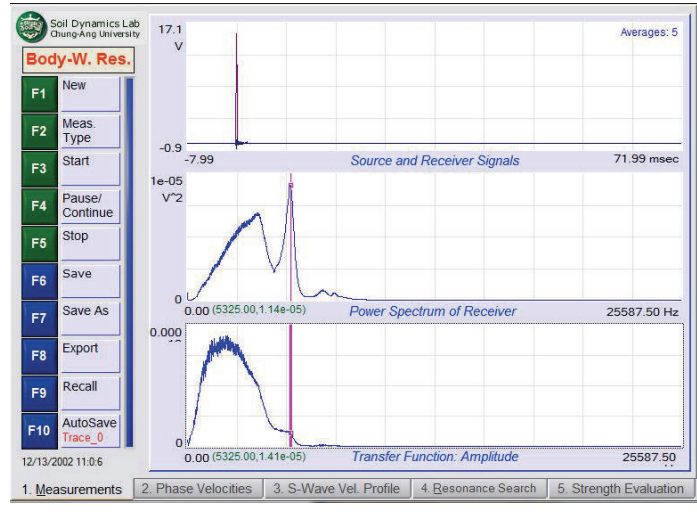

(a)

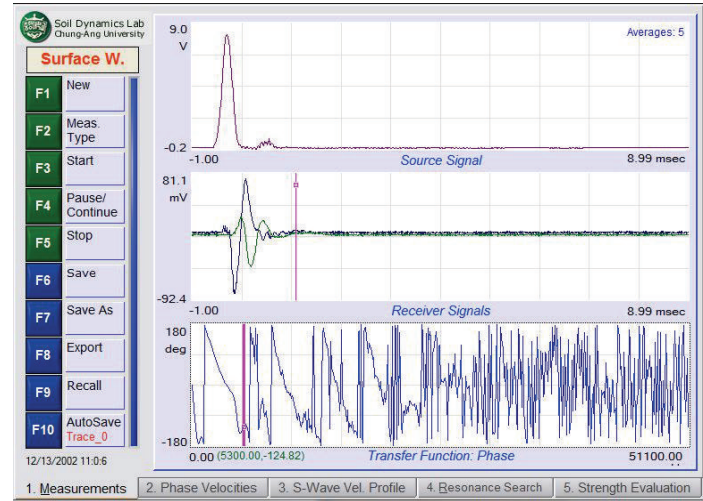

(b)

FIGURE 5: (a) Frequency spectrum of body wave resonance measurement and (b) Phase angle spectrum from surface wave measurement. 


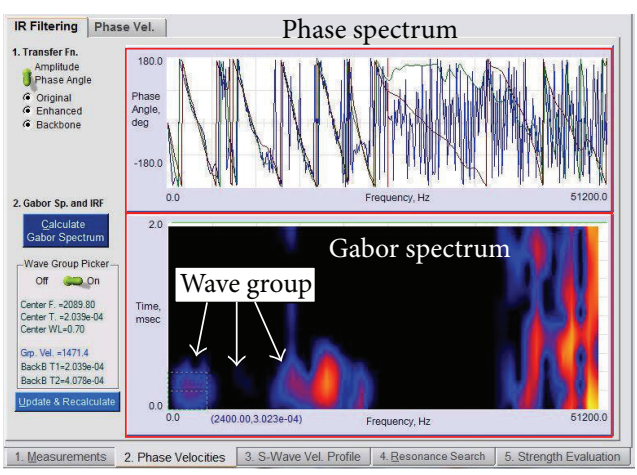

FIGURE 6: Gabor spectrum (contains wave groups).

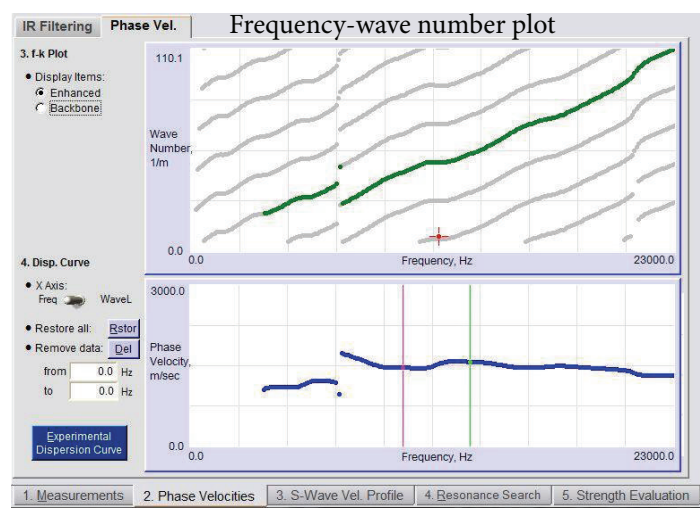

FIGURE 7: Phase velocity dispersion curve.

spectrum. The Gabor spectrum is the spectrum that displays the concentration of energy that can be produced from the propagation of the wave groups and is used to separate clearly the frequency range of the wave groups propagated at high and low modes. Thus, the arrival of the wave group on the pavement layers and the frequency components belonging to the group of the wave can be determined.

The dispersion curves for the phase velocity are then produced from the enhanced spectrum, as shown in Figure 7. The shear wave velocity can be determined from the velocity dispersion curves after going through the inversion analysis. The parameters used in this analysis are shown in Table 1 . The data undergoes a layering process and then inverse analysis is done once again to determine the thickness of each pavement layer based on the shear wave velocity ( $S$ wave) by assuming that the thickness of the pavement layer structure is equal to the resonant wavelength. This analysis uses the phase velocity dispersion curve with the lowest RMS value resulting from the layering process. A comparison of the dispersion curve obtained theoretically and experimentally is depicted in Figure 8.

In order to determine the thickness of the pavement more precisely, a second analysis involving the resonant frequency search is done. By default, this search technique is designed to determine the thickness of the pavement layer structure where the thickness of the resonant frequency is equal to the resonant frequency measured. This analysis involves

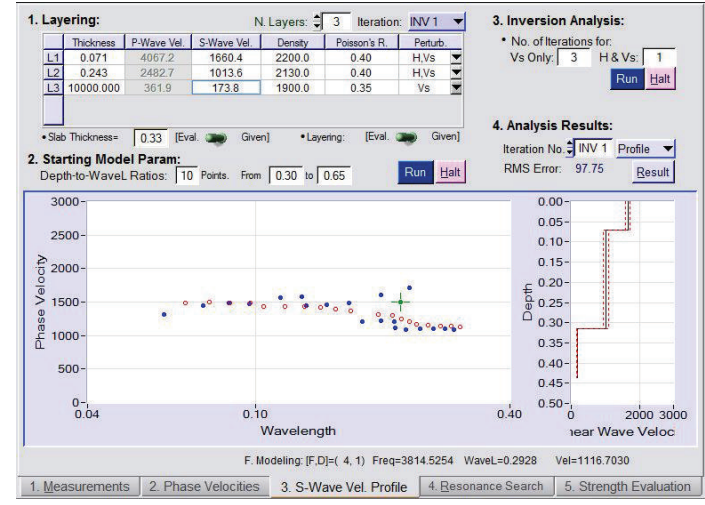

FIGURE 8: Inversion analysis (determination of the thickness of each pavement layer based on the shear wave velocity ( $S$ wave $)$ ).

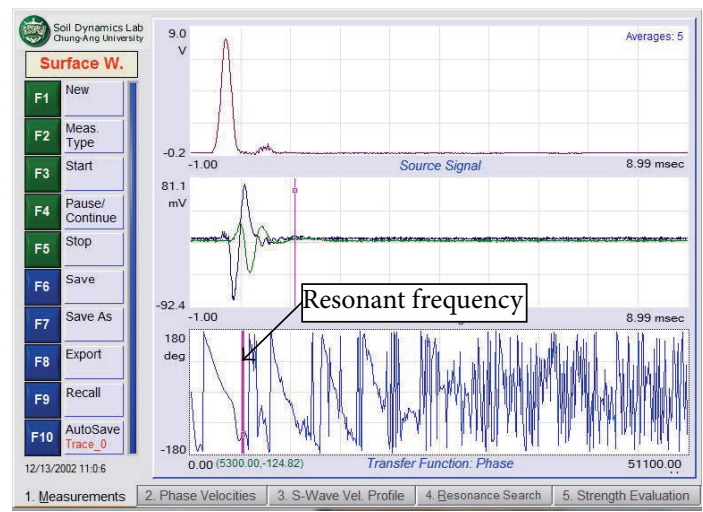

FIGURE 9: Resonant frequency of phase spectrum at transfer function.

TABLE 1: The parameters used in the analysis.

\begin{tabular}{lcc}
\hline Layer & Density & Poisson's ratio \\
\hline 1 & 2200 & 0.4 \\
2 & 2130 & 0.35 \\
3 & 1900 & 0.33 \\
\hline
\end{tabular}

finding the resonant frequency of the phase spectrum of the transfer function that is produced by surface waves (Figure 9). This frequency is used as a reference for finding the peak frequency of the power spectrum at the first receiver, as shown in Figure 10, and then applied to determine the resonant frequency of the body waves produced.

As explained by Joh et al. [5], the frequency response curve consists of more than 400 frequencies to identify the resonant frequency and takes about 15 minutes to be analysed. Special algorithms have been created to analyse the frequency whereby it is divided into two analytical analyses of rough sweep and fine sweep. Then, four to five different layering systems have been set up and the results of this analysis form a graph of spectral displacements for the thickness assumptions whereby the blue line represents the frequency of rough sweeping and the red line represents the frequency of the fine sweeping (Figure 11(a)). The graph of the thickness 
TABLE 2: Average of shear wave velocity and elastic modulus values.

\begin{tabular}{|c|c|c|c|}
\hline Numbers & Location & $\begin{array}{l}\text { Average of shear wave velocity values } \\
\qquad V_{S}(\mathrm{~m} / \mathrm{s})\end{array}$ & $\begin{array}{c}\text { Average of elastic modulus values } \\
E(\mathrm{MPa})\end{array}$ \\
\hline 1 & Gelanggang Road & 1099.071 & 7705.032 \\
\hline 2 & Lebuh Ilmu Road & 767.788 & 3928.877 \\
\hline 3 & Bunga Raya Road & 1394.263 & 12263.678 \\
\hline 4 & Syed Nasir Road & 1224.650 & 9634.834 \\
\hline 5 & Lingkungan Johan & 1065.338 & 8020.023 \\
\hline 6 & Wira Road (Kolej Keris Mas) & 1615.607 & 16999.285 \\
\hline 7 & Wira Road (UKM Transportation Unit) & 1643.212 & 17726.012 \\
\hline 8 & Nik Ahmed Kamil Road & 1460.126 & 13341.513 \\
\hline 9 & Temuan Road & 897.858 & 5867.526 \\
\hline 10 & Tun Abdullah Mohd Salleh Hall & 1173.139 & 8927.070 \\
\hline 11 & Tun Ismail Ali Road (gate number 3) & 1567.664 & 15641.718 \\
\hline 12 & Tun Ismail Ali Road (Faculty of Law) & 846.050 & 4863.557 \\
\hline 13 & Faculty of Engineering's administrative buildings & 1266.959 & 14719.172 \\
\hline 14 & Faculty of Engineering's academic buildings & 1263.280 & 13435.592 \\
\hline 15 & Faculty of Science and Technology's new buildings & 1160.235 & 8643.595 \\
\hline
\end{tabular}

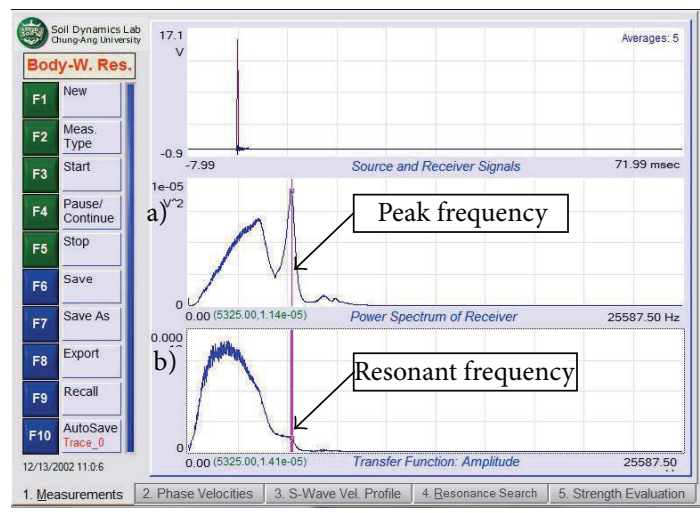

FIGURE 10: Frequencies generated at (a) power spectrum receiver and (b) transfer function (obtain resonant frequency to determine thickness of asphalt surface layer).

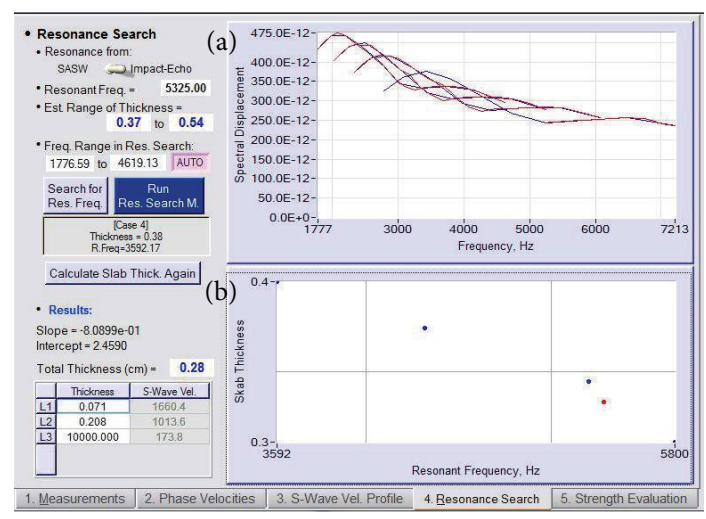

FIGURE 11: Analysis of resonant frequency search. (a) Spectral spectrum shifted graph for thickness assumptions (set up four or five different layering systems). (b) Relationship between the thicknesses of the structure layer and the resonant frequency (red dot represents the thickness of asphalt surface layer). and corresponding frequency is then plotted on a logarithmic scale and the relationship is found to be linear (Figure 11(b)). By using the resonant frequency (represented as a red dot) identified from the initial analysis, the thickness of the pavement layer structure can be determined.

5.4. Elastic Modulus of the Material. From the signal data obtained, the phase velocity dispersion curve can be derived through inverse analysis to produce the shear wave velocity profile. The elastic modulus of the asphalt surface layer material can be determined by using the value of this shear wave velocity using (2). Table 2 shows the average value of the shear wave velocity and the average value of the elastic modulus of the material obtained in this study. Poisson's ratio has been estimated and the material mass density of the Poisson ratio used for the asphalt and aggregate mixture is 0.4 [15] and the unit weight of the material is $2200 \mathrm{~kg} / \mathrm{m}^{3}$ [16]. The comparison between the theoretical dispersion curve and the experimental dispersion curve that produces the lowest rootmean square (RMS) error is used during the processing and analysis of data to obtain the shear wave values.

By using the average shear wave velocity data, the value of the elastic modulus for the asphalt surface layer can be determined. Within the range of temperatures that can occur in road pavements in Malaysia, elastic modulus values will vary from a few hundred MPa at high pavement temperatures to about $3000 \mathrm{MPa}$ at the low end of pavement temperatures [15]. However, this study does not consider a low temperature environment because the temperature in Malaysia rarely falls below $30^{\circ} \mathrm{C}$ in daylight hours and is usually in the range of 35 to $45^{\circ} \mathrm{C}$. From the calculation (Table 2), it was found that the range value of the elastic modulus is between $3929 \mathrm{MPa}$ and $17726 \mathrm{MPa}$. The average elastic modulus obtained was higher than the standard set by the IKRAM Group Sdn. Bhd., which is $2500-3200 \mathrm{MPa}$. However, some of the elastic values are recorded within the Malaysian Public Work Department 
TABLE 3: A comparison between the average asphalt layer thickness and the design proposed by MDD UKM.

\begin{tabular}{|c|c|c|c|c|}
\hline Numbers & Location & $\begin{array}{l}\text { Average asphalt layer thickness } \\
(\mathrm{m})\end{array}$ & $\begin{array}{l}\text { Design of MDD UKM } \\
(\mathrm{m})\end{array}$ & $\begin{array}{c}\text { Difference } \\
(\%)\end{array}$ \\
\hline 1 & Gelanggang Road & 0.05638 & \multirow{15}{*}{0.100} & 43.62 \\
\hline 2 & Lebuh Ilmu Road & 0.04413 & & 55.87 \\
\hline 3 & Bunga Raya Road & 0.05681 & & 43.19 \\
\hline 4 & Syed Nasir Road & 0.05557 & & 44.43 \\
\hline 5 & Lingkungan Johan & 0.05020 & & 49.80 \\
\hline 6 & Wira Road (Kolej Keris Mas) & 0.04556 & & 54.44 \\
\hline 7 & Wira Road (UKM Transportation Unit) & 0.07400 & & 26.00 \\
\hline 8 & Nik Ahmed Kamil Road & 0.06409 & & 35.91 \\
\hline 9 & Temuan Road & 0.04480 & & 55.20 \\
\hline 10 & Tun Abdullah Mohd Salleh Hall & 0.05046 & & 49.54 \\
\hline 11 & Tun Ismail Ali Road (gate number 3) & 0.06062 & & 39.38 \\
\hline 12 & Tun Ismail Ali Road (Faculty of Law) & 0.05786 & & 42.14 \\
\hline 13 & Faculty of Engineering's administrative buildings & 0.04940 & & 50.60 \\
\hline 14 & Faculty of Engineering's academic buildings & 0.05467 & & 45.33 \\
\hline 15 & Faculty of Science and Technology's new buildings & 0.04700 & & 53.00 \\
\hline
\end{tabular}

(PWD) standard (1200 MPa for wearing course and $1600 \mathrm{MPa}$ for binder course) [15]. This might happen because the quality of the material at each location is different according to when the pavement was constructed.

From the measurements, high average elastic modulus values were recorded due to the influence of traffic load and pavement construction age [1]. The locations that have a high average elastic modulus, namely, Bunga Raya Road, Wira Road (Keris Mas College), Wira Road (UKM Transport Unit), Nik Ahmed Kamil Road, Tun Ismail Ali Road (gate number 3), and Faculty of Engineering's academic building, experience low traffic load while the Faculty of Engineering's administrative building is newly built. Rosyidi et al. [17] and Rosyidi [16] have studied the stiffness of new pavement and found that the average value of the elastic modulus on new roads is high. Therefore, it can be concluded that the elastic modulus value for new pavement is high compared to old pavement; a high elastic modulus represents the high strength of the pavement structure layers. However, the quality of pavement structure decreases with time and the rate of decrease depends on the traffic load, the quality of the materials, and environmental influences.

5.5. The Thickness of the Asphalt Surface Layer. The actual thickness of the asphalt surface layer is determined through the analysis of the wave propagation model, which requires a resonant frequency search. The thickness obtained was then compared to the design thickness specified by the Management Development Department, UKM (MDD UKM), and the Malaysian PWD standards. Table 3 shows the comparison between the average asphalt surface layer thickness measured in this study and the design thickness of MDD UKM.

The research results reveal that the average thickness of the asphalt surface layer lies in the range between 0.04 and $0.08 \mathrm{~m}$. Meanwhile, the thickness of the asphalt surface layer specified by Malaysian PWD is divided into two layers, namely, the wearing layer and the binder layer, and the range of each layer is 0.04 to $0.05 \mathrm{~m}$ and 0.04 to $0.1 \mathrm{~m}$, respectively. Taking into account these two layers as the surface layer of asphalt, the range obtained is 0.04 to $0.14 \mathrm{~m}$. The difference between the average thickness measured and the design thickness of MDD UKM is between 20 and 60\%; the lowest difference of $26 \%$ was noted for Wira Road (UKM Transportation Unit) and the highest difference of $55.87 \%$ was recorded for Lebuh Ilmu Road. The average thickness of the asphalt surface layer is $0.04413 \mathrm{~m}$. SASW and borehole studies done by Rosyidi [16] at Lebuh Ilmu Road revealed that the average thickness of the asphalt surface layer is $0.059 \mathrm{~m}$ and $0.0666 \mathrm{~m}$, respectively.

Rosyidi [16] also conducted a study using the SASW and borehole method at Lebuh Ilmu Road. The results of this study show that the average thickness of the surface layer of asphalt is $0.059 \mathrm{~m}$ for the SASW method and $0.067 \mathrm{~m}$ for the borehole method. The difference in the thickness of the surface layer is due to the fact that the road was not properly constructed according to the standard and differences in the wave detected on the Gabor spectrum when IR filtration was carried out. This is because experience in analysing the spectrum of the wave data is needed to help the filtration process. Therefore, it can be concluded that the average thickness of the asphalt layer in this study is still within the allowable range of the standards set by Malaysian PWD and the design is almost similar to the design thickness of MDD UKM.

\section{Conclusions}

The following conclusions have been drawn from the study.

(i) The range of values of the elastic modulus of asphalt pavement materials obtained in this study, which are between $3929 \mathrm{MPa}$ and $17726 \mathrm{MPa}$, is higher than the elastic modulus range set by the IKRAM Group Sdn. 
Bhd. However, some of the elastic values obtained are recorded within the Malaysian PWD standard. This happened because the quality of the material at each location is different according to when the pavement was constructed.

(ii) The average thickness of the surface layer of asphalt as measured by the ERS method is between 0.04 and $0.08 \mathrm{~m}$. This is still within the range of the standards set by Malaysian PWD, which is 0.04 to $0.14 \mathrm{~m}$. Moreover, the difference between the thickness of the asphalt surface layer obtained in this research and the design thickness specified by the MDD UKM does not exceed $60 \%$.

(iii) The study shows that the ERS method using the PiScanner is able to measure the stiffness and thickness of the surface layer of asphalt according to the prescribed standards. Therefore, it can be concluded that this technique can be used not only for rigid pavements but also for determining the thickness and stiffness of flexible pavements.

\section{Conflict of Interests}

The authors declare that there is no conflict of interests regarding the publication of this paper.

\section{Acknowledgment}

The authors express their gratitude to the University Kebangsaan Malaysia (UKM) for the financial support of this work (GUP-2013-014 and DLP-2013-028).

\section{References}

[1] M. O. Hamzah, A. Hasan, and M. R. Karim, Reka Bentuk Jalan Raya UntukJurutera, Dewan Bahasa dan Pustaka, Kuala Lumpur, Malysia, 1992.

[2] A. Giannopoulos and N. Diamanti, "A numerical investigation into the accuracy of determining dielectric properties and thicknesses of pavement layers using reflection amplitude GPR data," in Proceedings of the Tenth International Conference Ground Penetrating Radar (GPR '04), pp. 655-658, Delft, The Netherlands, June 2004.

[3] M. Y. Shanin, Pavement Management for Airports, Roads and Parking Lots, Chapman \& Hall, New York, NY, USA, 1994.

[4] M. F. Aouad, K. H. Stokoe II, and J. M. Röesset, Evaluation of Flexible Pavements and Subgrades Using the Spectral-Analysisof-Surface-Waves (SASW) Method, Center for Transportation Research, Bureau of Engineering Research, the University of Texas at Austin, 1993.

[5] S. H. Joh, M. Cho, T. Kang, S. A. Kwon, and J. H. Nam, "Pavement integrity scanner to characterize modulus contrast between near-surface and deeper material in concrete pavements," Transportation Research Record, no. 2070, pp. 39-48, 2008.

[6] N. J. Cho, S. H. Joh, and S. A. Kwon, "Non-destructive in-place strength profiling of concrete pavements by research search technique," in Proceedings of the 86th Annual Meeting of the Transportation Research Board, Washington, DC, USA, 2007.
[7] K. H. Stokoe II, S. G. Wright, J. A. Bay, and J. M. Röesset, "Characterization of geotechnical sites by SASW method," in Technical Review: Geophysical Characterization of Sites, R. D. Woods, Ed., pp. 15-25, Oxford Publishers, New Delhi, India, 1994.

[8] N. Gucunski and R. D. Woods, "Numerical simulation of the SASW test," Soil Dynamics and Earthquake Engineering, vol. 11, no. 4, pp. 213-227, 1992.

[9] V. Ganji, N. Gucunski, and S. Nazarian, "Automated inversion procedure for spectral analysis of surface waves," Journal of Geotechnical \& Geoenvironmental Engineering, vol. 124, no. 8, pp. 757-770, 1998.

[10] M. Bath, Spectral Analysis in Geophysics, Elsevier Science, Amsterdam, The Netherlands, 1974.

[11] G. Nolet and G. F. Panza, "Array analysis of seismic surface waves: Limits and possibilities," Pure and Applied Geophysics, vol. 114, no. 5, pp. 775-790, 1976.

[12] M. Sansalone, "Impact-echo: the complete story," ACI Structural Journal, vol. 94, no. 6, pp. 777-786, 1997.

[13] S. L. Karmer, Geotechnical Earthquake Engineering, Prentice Hall, New Jersey, NJ, USA, 1996.

[14] E. J. Yoder and M. W. Witczak, Principles of Pavement Design, John Wiley \& Sons, New York, NY, USA, 1975.

[15] Malaysian Public Works Department (PWD), "Manual for the Structural Design of Flexible Pavement," TJ 5/85 (Amendment of 2013). Kuala Lumpur, Malaysia, 2013.

[16] S. A. Rosyidi, Penilaian kekukuhan dinamik bahan lapisan turapan menggunakan kaedah SASW [MSc Thesis], Universiti Kebangsaan Malaysia, Malay, Malaysia, 2004.

[17] S. A. Rosyidi, K. A. M. Nayan, M. R. Taha, and M. M. Mustafa, "Pengukuran sifat dinamik perkerasan lentur menggunakan metode Spectral-Analysis-of-Surface-Wave (SASW)," in Proceedings of the Prosiding Simposium Forum Studi Transportasi antara Perguruan Tinggi V, 2002, (Indonesian). 

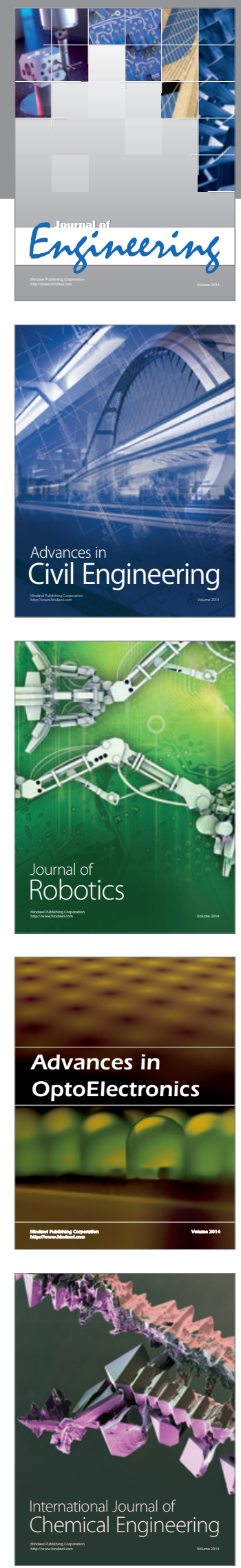

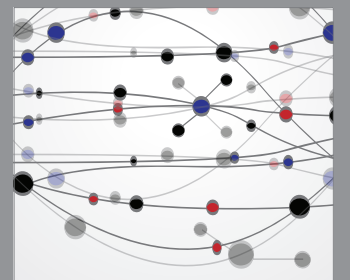

The Scientific World Journal
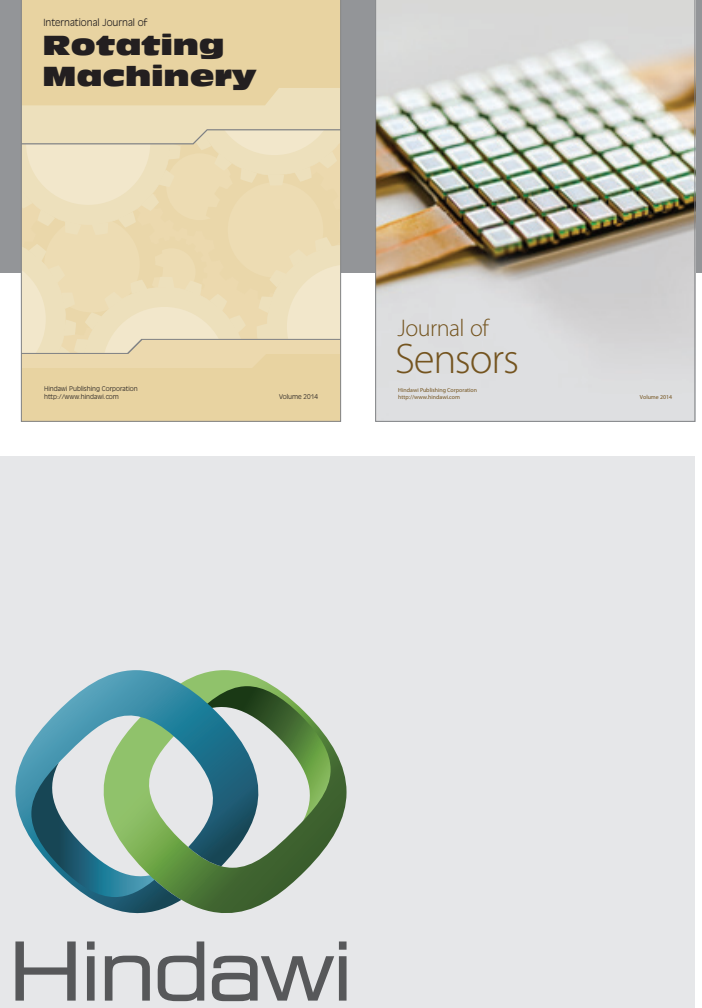

Submit your manuscripts at http://www.hindawi.com
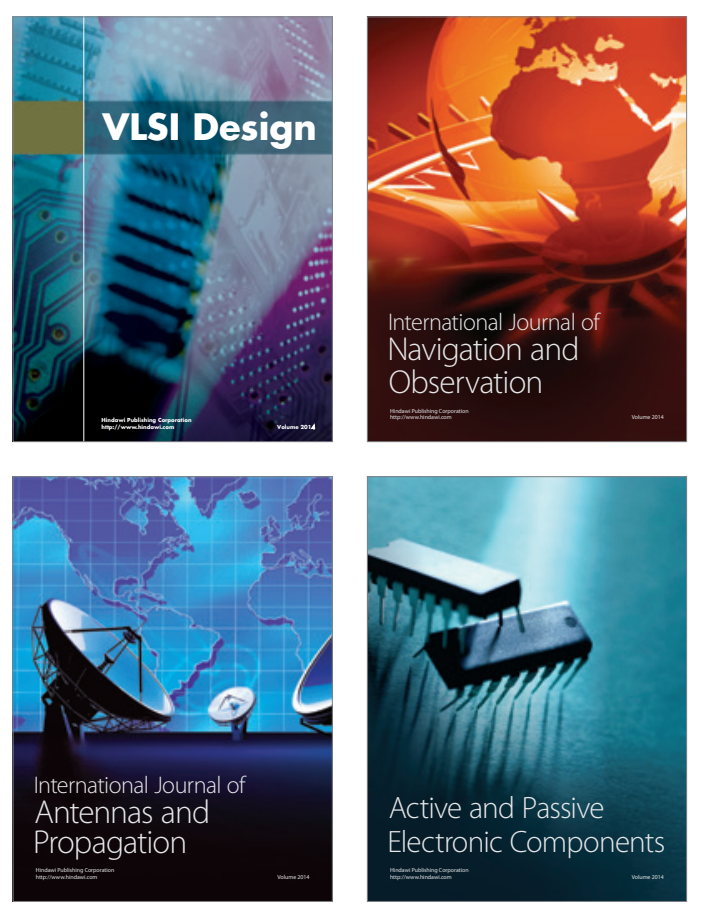
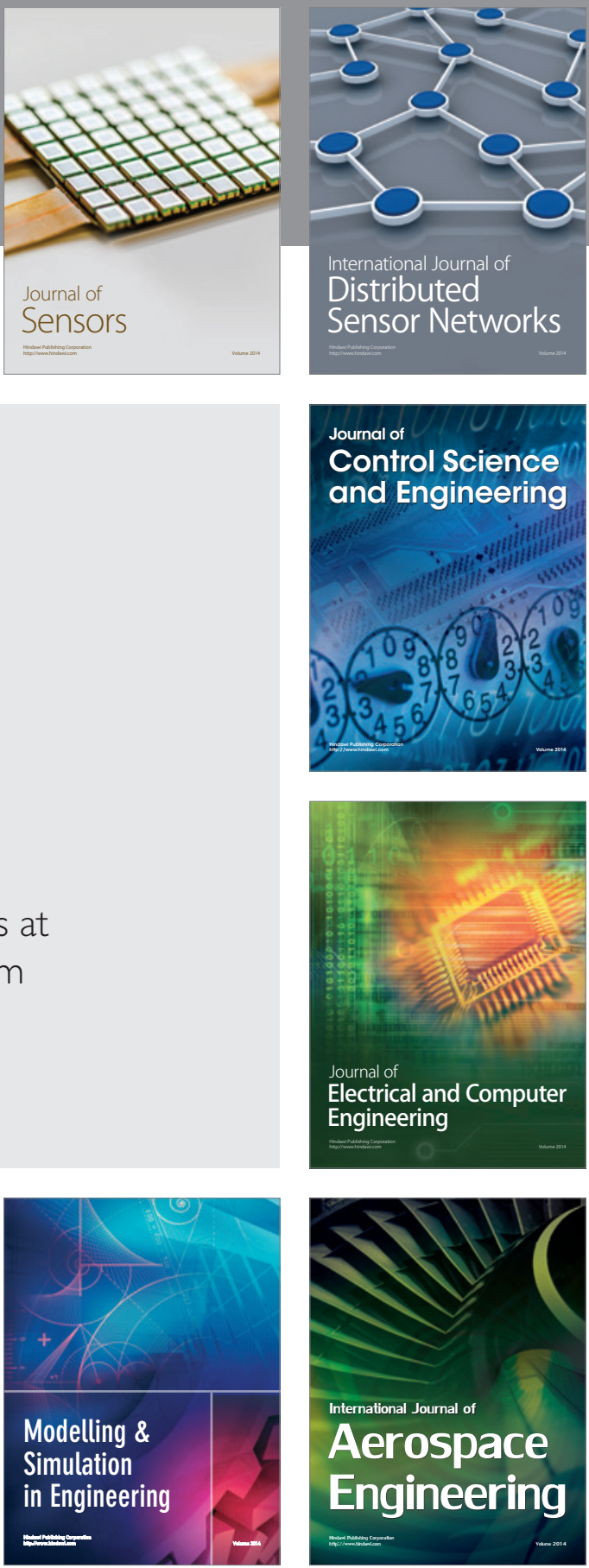

Journal of

Control Science

and Engineering
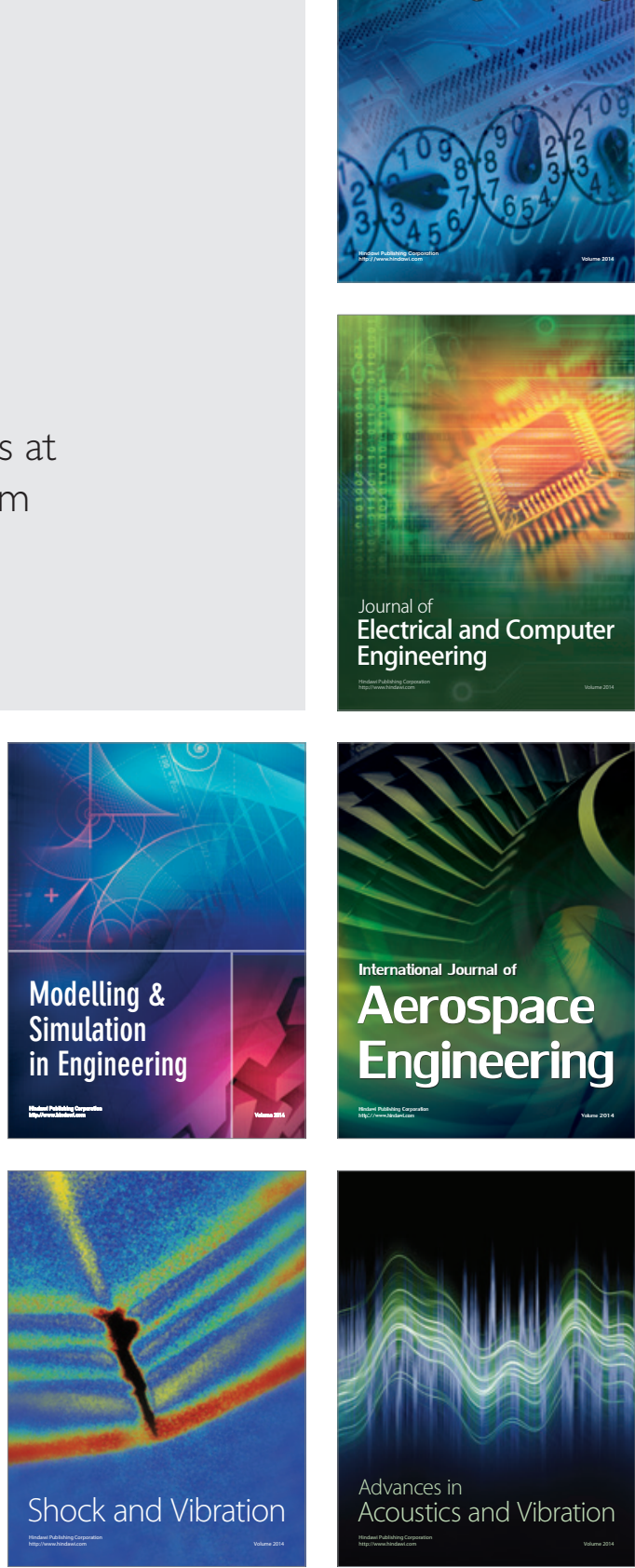